\title{
Cys-Loop Receptor Ionic Channels: Structure, Function, and Regulation
}

\author{
P. D. Bregestovski \\ Mediterranean Institute of Neurobiology (INMED), Marseille, France; \\ e-mail: pbreges@inmed.univ-mrs.fr
}

DOI: $10.1134 / \mathrm{S} 1990747809030131$

The Cys-loop superfamily constitutes a major class of receptor-operated ion channels. Functional channel module contains five protein subunits, with a signature sequence of 13 residues flanked by covalently bound cysteines, situated between binding and channel domains. In vertebrates, Cys-loop receptors are subdivided into cation- and anion-selective channels, corresponding to excitatory receptors activated by acetylcholine (ACh) or serotonin, and inhibitory receptors activated by GABA or glycine.

Two recent breakthroughs have accelerated our understanding of the molecular structure of the Cysloop superfamily. First, the discovery of acetylcholinebinding protein (AChBP) from the freshwater snail Lymnaea stagnalis, and the determination of its struc- ture at a resolution of $2.7 \AA$. This stimulated homology modeling of ligand-binding domains using AChBP as the template. Second, electron microscopy of ACh receptors from Torpedo at a resolution of $4 \AA$, which revealed the protein backbone and bulky side chains of the compete receptor protein.

Cys-loop receptors are involved in rapid synaptic neuro-muscular and neuro-neuronal communication. The functioning of these channels is regulated via external, intracellular and transmembrane domains. As an example, we have shown that cytoplasmic $\mathrm{Ca}^{2+}$ leads to rapid potentiation of responses to glycine via $\mathrm{Ca}^{2+}$ binding protein $(\mathrm{CaBP})$. This mechanism may play an important role in $\mathrm{Ca}^{2+}$-dependent modulation of rapid synapses in the nervous system of vertebrate. 